\title{
SOME INVESTIGATIONS ON THE ANISOTROPY OF THE CHEMICAL ETCHING OF (hk 0) AND (h hl) SILICON PLATES IN A NaOH 35\% SOLUTION. PART II: 3D ETCHING SHAPES, ANALYSIS AND COMPARISON WITH KOH 56\%
}

\author{
C. R. TELLIER ${ }^{\mathrm{a}, \mathrm{b}, *}$, C. A. HODEBOURG ${ }^{\mathrm{a}, \mathrm{b}}$ and S. DURAND ${ }^{\mathrm{c}}$
}

${ }^{a}$ Laboratoire de Chronométrie Electronique et Piezoélectricité, Ecole Nationale Supérieure de Mécanique et des Microtechniques, 26 Chemin de l'Epitaphe, 25030 Besançon cedex, France; ${ }^{b}$ Institut des Microtechniques de FrancheComté, Avenue de l'Observatoire, 25030 Besançon cedex, France; ${ }^{\mathrm{c}}$ Laboratoire d'Acoustique de l'Université du Maine, Avenue Olivier Messiaen, 72085 Le Mans cedex 9, France

(Received 20 June 2001; In final form 20 August 2001)

This paper deals with the micromachining of various $(\mathrm{h} \mathrm{k} 0)$ and $(\mathrm{h} h l)$ membrane-mesa structures in a $\mathrm{NaOH} 35 \%$ solution. Final etching shapes of micromachined structures show a marked anisotropy of type 1. Etching shapes are analysed in terms of the kinematic and tensorial model for the anisotropic dissolution of crystals. Some of crystallographic planes limiting membranes and mesa are identified from a stereographic analysis of top contours. Conclusions of this study are in close agreement with a previous work.

\section{INTRODUCTION}

Micromachined 3D silicon structures are widely used [1-3] as sensing elements for mechanical sensors. Most of structures are micromachined in $\left\{\begin{array}{lll}1 & 0 & 0\end{array}\right\}$ and $\left\{\begin{array}{lll}1 & 1 & 0\end{array}\right\}$ silicon wafers. But when the sensing principle is based on the piezoresistive properties of the silicon crystal [4] it may be of interest to work with piezoresistive elements diffused

*Corresponding author. Tel.: (0381) 402830; Fax: (0381) 885714;

E-mail: ctellierens $2 \mathrm{~m}$.fr 
on $(\mathrm{h} h l)$ planes $[5,6]$. In a wet etching process the final shape of etched microstructures is determined by firstly, the orientation of the wafer (i.e. firstly, by the angles of cut $\varphi_{\mathrm{o}}$ and $\theta_{\mathrm{o}}$ [7]) and secondly, by the direction $D_{A}$ of alignment of the mask $[8,9]$. So when we are concerned with the micromachining of 3D structures in $(\mathrm{h} h l)$ planes a more precise knowledge of the dissolution slowness surface is necessary to predict final etching shapes.

In the first part of this paper [10] devoted to $2 \mathrm{D}$ etching shapes some conclusions on the extrema of the dissolution slowness were drawn. In the second part attempts are made in the one hand, to verify these preliminary conclusions and in the other hand, to identify the facets that limit micromachined structures such as membranes and mesa.

\section{EXPERIMENTS}

\subsection{Experimental Details}

Thin different ( $\mathrm{h} \mathrm{k} 0)$ and $(\mathrm{h} h l)$ silicon plates $(300 \mu \mathrm{m}$ thick) were cut in a silicon ingot. A final mechanical polishing of surface was performed that ensures an average roughness $\mathrm{Ra}$ of about $0.01 \mu \mathrm{m}$. The two faces of plates were firstly coated with a thermally grown silicon dioxide layer ( $1.2 \mu \mathrm{m}$ thick) and then patterned by test masks using a conventional photolithography process. Combinations of circular and rectangular masks (Fig. 1) were used in order to obtain 3D "membrane-mesa" structures. All structures were chemically etched in a

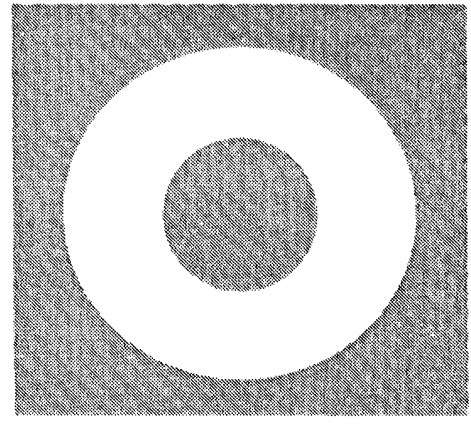

A : Circular masks

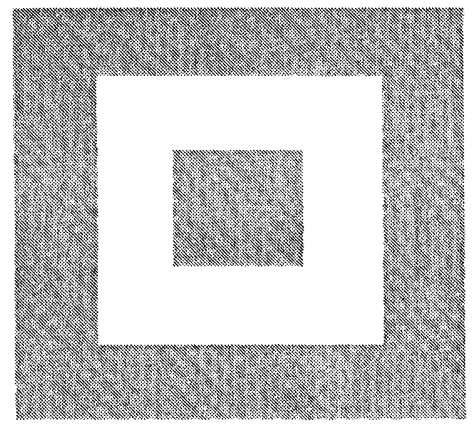

B : Square masks

FIGURE 1 The combinations of "circular" and "square" masks (in grey). 
$35 \% \mathrm{NaOH}$ solution maintained at a constant temperature of about $60^{\circ} \mathrm{C}$. Complementary experiments on the micromachining of silicon structures were also performed using a $\mathrm{KOH} 56 \%$ etching bath.

Micromachined structures were observed by Scanning Electron Microscopy (SEM). In addition constant-level contour diagrams were furnished by a $3 \mathrm{D}$ computer-based mechanical profilometer.

\subsection{Structures Micromachined in a $\mathrm{NaOH} \mathrm{35 \%} \mathrm{Solution}$}

\subsubsection{SEM Observations}

First let us consider micromachined 3D structures as obtained when we start with circular masks. Figures 2 and 3 give SEM images of

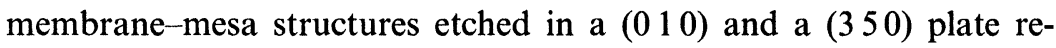
spectively. One can distinguish that the four-fold symmetry associated with the $\left[\begin{array}{lll}0 & 1 & 0\end{array}\right]$ direction is fulfilled by the $\left(\begin{array}{lll}0 & 1 & 0\end{array}\right)$ structure whereas the (3 50) structure satisfies to the mirror symmetry related to the $\left(\begin{array}{ll}0 & 01\end{array}\right)$ plane. Clearly these two images reveal that the top contour of a membrane cut in the upper surface differs from the top contour related to the mesa. Consequently facets that bound the membrane do not

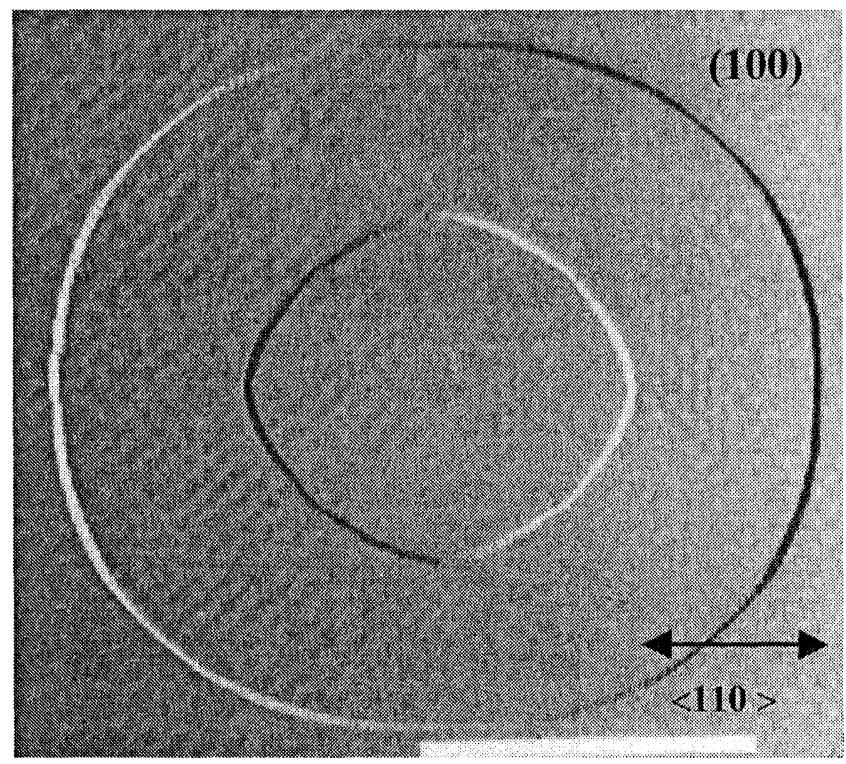

FIGURE 2 SEM image of the "circular" (1 000$)$ membrane-mesa structure. 


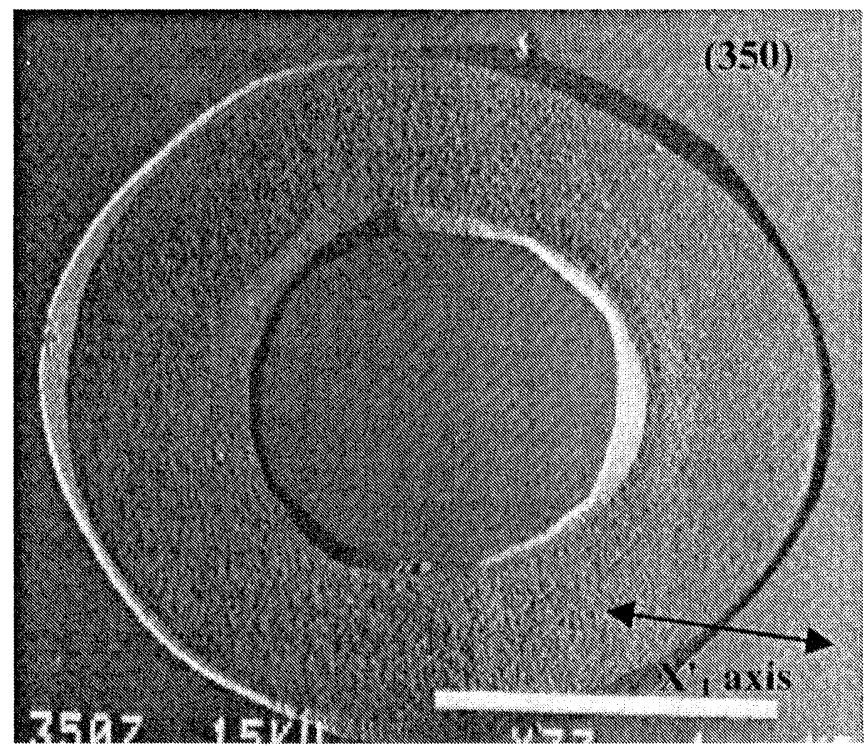

FIGURE 3 SEM image of the "circular" (3 50) membrane-mesa structure.

limit the mesa even if at the first sight we can see some correspondence (Fig. 3) between shoulders that meet the bottom surface of a membrane and of the corresponding mesa.

Figure 4 shows final "circular" membrane-mesa structures etched in various $(\mathrm{h} h l)$ plates. On SEM images the $\langle 110\rangle$ direction corresponds to the vertical direction so as expected the mirror symmetry that can be depicted on these images is associated with a $\left\{\begin{array}{lll}1 & 1 & 0\end{array}\right\}$ plane. These figures call for several remarks:

(i) As mentioned earlier different facets surround membranes and corresponding mesa.

(ii) $\left\{\begin{array}{lll}1 & 1 & 1\end{array}\right\}$ planes that dissolve very slowly bound the major portion of membranes. In particular the inclination of the $\left\{\begin{array}{lll}1 & 1 & 1\end{array}\right\}$ planes that intersect the $(\mathrm{h} h l)$ reference surface along the vertical $\left\langle\begin{array}{lll}1 & 1 & 0\end{array}\right)$ direction depends on the angle of cut.

(iii) For the (1 18 ) plate that lies in the vicinity of the $\left(\begin{array}{lll}0 & 0 & 1\end{array}\right)$ plane we can see (Fig. 4a) that $\{100\}$ planes which correspond to small protuberances of the dissolution slowness surface [10] participate also to the final membrane. 

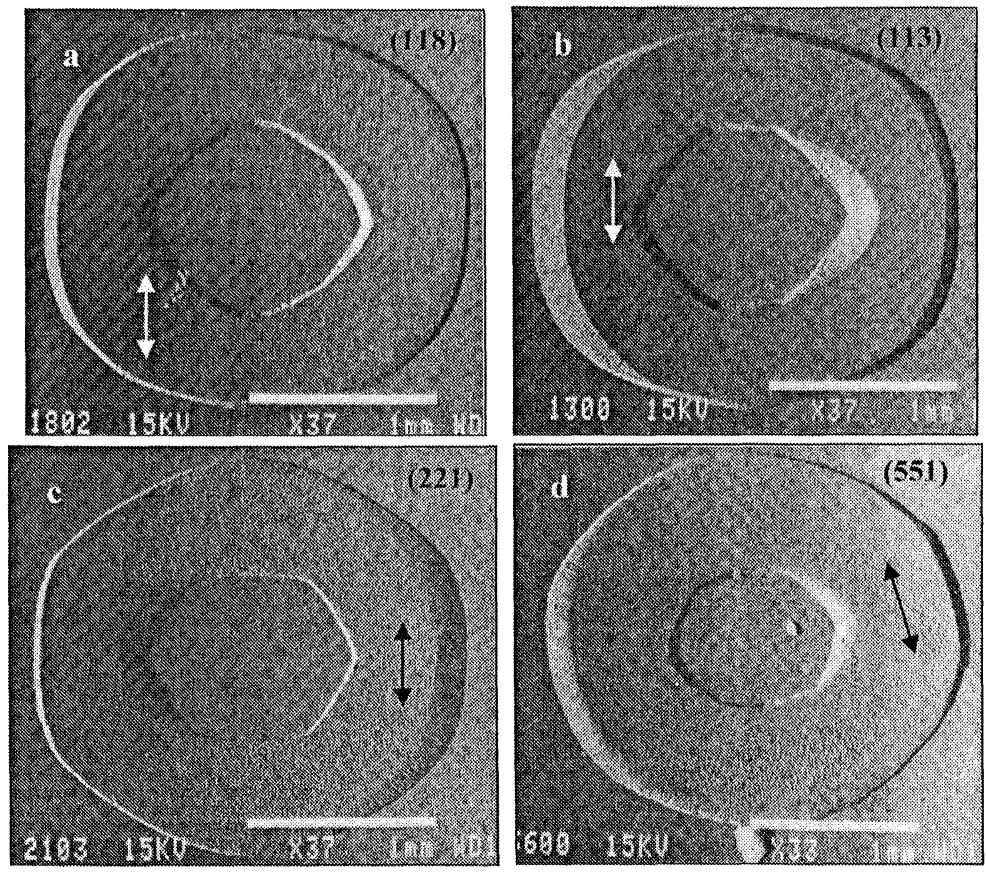

FIGURE 4 SEM images of "circular" ( $\mathrm{h} \mathrm{h} l$ ) membrane-mesa structures, a, b, c and d are for (118), (113), (221) and (551) structures respectively. Arrows indicate the direction of the $\langle 110\rangle$ axis.

(iv) If we turn attention to $(\mathrm{h} h l)$ mesa we observe that the most significant changes in shape occur when the angle of cut $\theta_{\mathrm{o}}$ is in the range $50^{\circ}-90^{\circ}$ (i.e. for $\left\{\begin{array}{llll}1 & 1 & 1\end{array}\right\}$ planes) with a rapid destruction of the fourfold symmetry related to the $\left(\begin{array}{lll}0 & 0 & 1\end{array}\right)$ plane $\left(\theta_{\mathrm{o}}=90^{\circ}\right)$. Effectively the top contour of $(\mathrm{h} h l)$ mesa is only slightly modified by changes in the angle of cut $\theta_{\mathrm{o}}$.

(v) As observed for other etchants $[8,9,11-13]$ a marked convex corner undercutting affects "circular" mesa.

We turn now attention to membrane-mesa structures micromachined on a given doubly rotated $(\mathrm{h} h l)$ plate when we use combinations of square masks aligned along various directions $D_{A}$. A direction of alignment $D_{A}$ makes an angle $\Psi_{A}$ with the $x_{3}^{\prime}$ axis that lies perpendicular to the $\left\langle\begin{array}{lll}1 & 1 & 0\end{array}\right\rangle$ direction ( $x_{1}^{\prime}$ axis). In this case it is also of interest 
to study the evolution in shape of structures with the direction of alignment $D_{A}$. Figures $5 \mathrm{a}-5 \mathrm{~d}$ reveal several features:

(1) Far from corners the corresponding lateral sides of structures are bounded by similar facets as expected for a $2 \mathrm{D}$ etching process $[9,14,15]$.

(2) $\left\{\begin{array}{lll}1 & 1 & 1\end{array}\right\}$ facets limit corners of membranes so that for two corners the top contours of all (1 113$)$ membranes are aligned along the $\langle 110\rangle$ direction (see for example corners $\mathrm{Cl}$ and $\mathrm{C} 3$ on Figure $5 \mathrm{~b}$ ).

(3) Only the corners of square mesa are concerned with the convex corner undercutting that for corresponding angular sectors are just those observed on the mesa of Figure 4b. But on Figure 5 less extent is observed for corner undercutting because in this case we are concerned with sectors of a mask whose radius tend to zero.
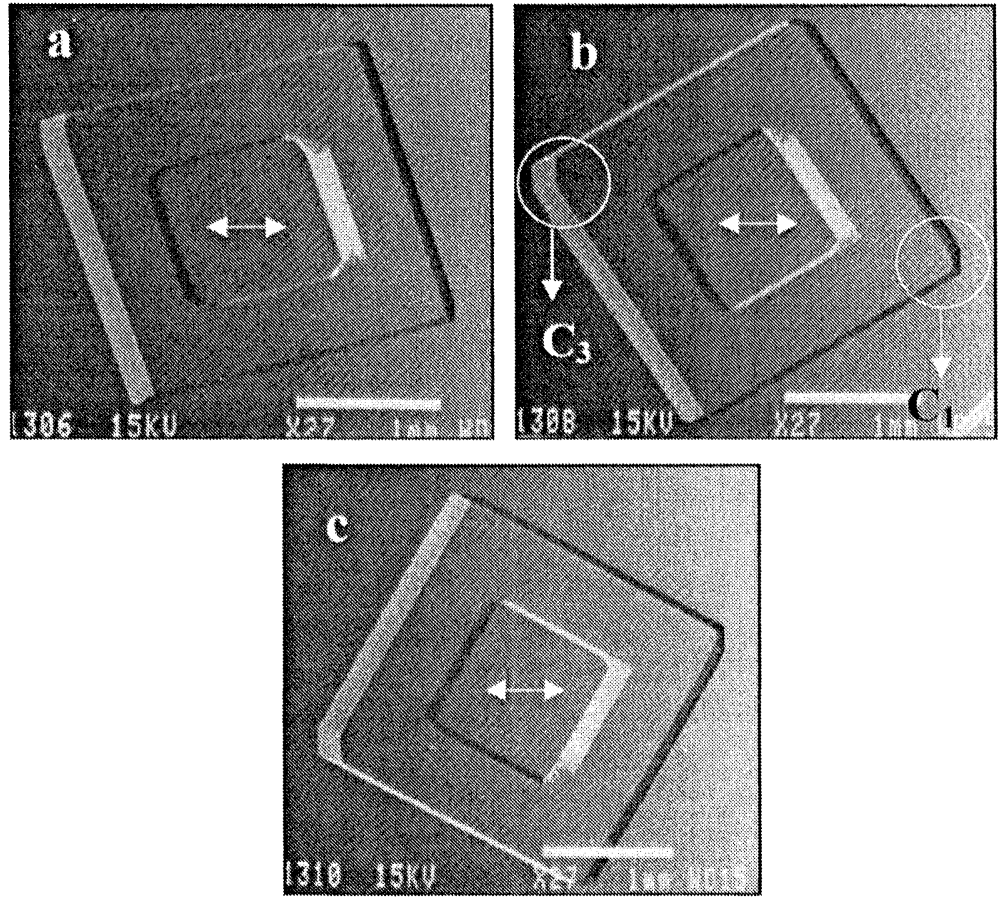

FIGURE 5 SEM images of differently aligned (113) mesa as obtained with square masks, a, b, c and d are for $\Psi_{A}=15^{\circ}, \Psi_{A}=30^{\circ}, \Psi_{A}=60^{\circ}$ respectively. Arrows indicate the direction of the $x_{3}^{\prime}$ axis. 
Features (1) and (2) account also for firstly, the directional effects observed (Fig. 6) on various sides of square (350) mesa and membranes and secondly for the convex corner undercutting. On the right side of SEM images (Figs. 6a and 6c) we see that the cross-sectional dissolution profile is composed of more than one facet. Moreover at mesa corners facets intersect to form bunches (Fig. 6d) as frequently observed [9] when limiting facets propagate within the crystal from the same point.

\subsubsection{Constant-Level Contour Diagrams}

The constant-level contour diagrams of Figure 7 give also evidence of mirror symmetries. But the major utility of these diagrams seems to furnish additional information on the top contour of structures. As pointed out earlier the membrane appear to be limited in majority by
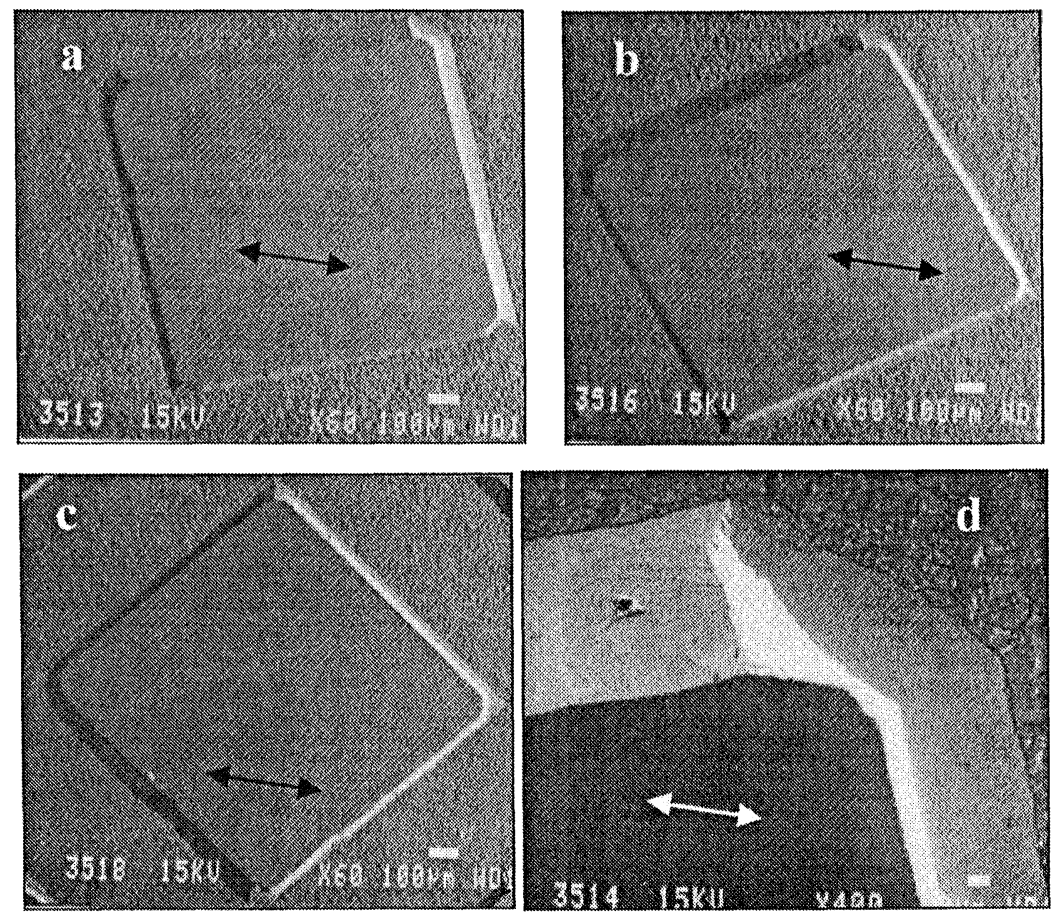

FIGURE 6 SEM images of differently aligned (350) mesa as obtained with square masks, $\mathbf{a}, \mathbf{b}$, and $\mathrm{c}$ are for $\Psi_{A}=20^{\circ}, \Psi_{A}=35^{\circ}, \Psi_{A}=50^{\circ}$ respectively. Arrows indicate the direction of the $x_{1}^{\prime}$ axis. The magnified image $\mathbf{d}$ shows bunching at a square corner. 

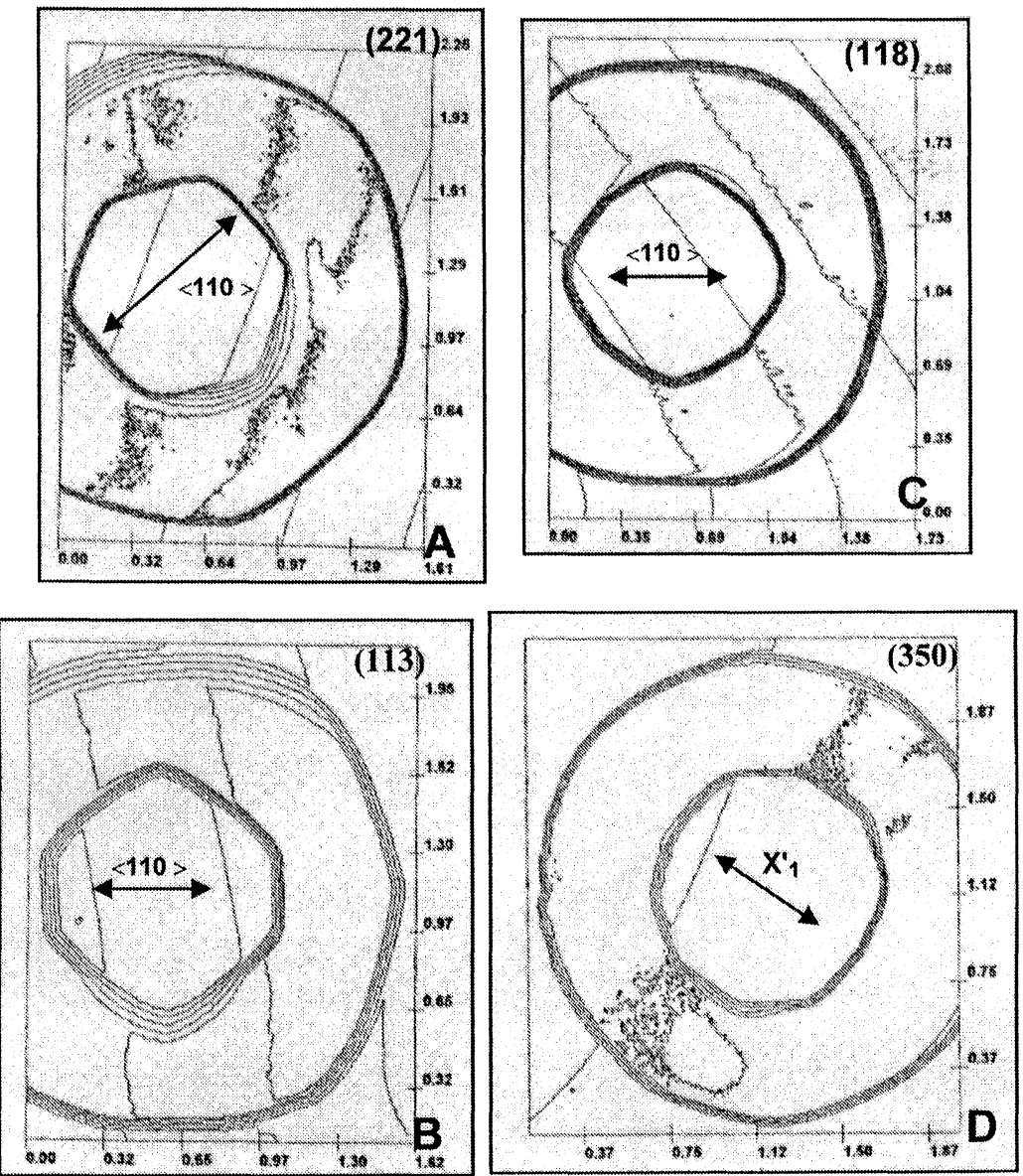

FIGURE 7 Constant-level contour diagrams of various "circular" (h $\mathrm{h} l$ ) membranemesa structures, A, B, C and D are for (221), (1 13 ), (1 1 1 8) and (3 50) structures respectively. Note that owing to the symmetry only a part of contour diagram is given for membranes.

$\left\{\begin{array}{lll}1 & 1 & 1\end{array}\right\}$ facets, behaviour commonly met $[8,9,12,13,16]$ in the micromachining of membranes. In contrast various $(\mathrm{h} h l)$ planes can bound mesa. Depending on the etching $\left\{\begin{array}{lll}1 & 1 & 2\end{array}\right\},\left\{\begin{array}{lll}2 & 2 & 1\end{array}\right\},\left\{\begin{array}{llll}3 & 3 & 1\end{array}\right\}$ and $\left\{\begin{array}{lll}1 & 1 & 3\end{array}\right\}$ planes have been identified $[12,13,17,18]$. So taking into account the diversity of results reported in literature a more complete analysis of the top and bottom contours of mesa is required. The top contour shape cut on the upper surface is composed of successive linear seg- 
ments. The number of segment depends on the cut. At first sight, eight segments constitute the top contour of the (221) mesa (Fig. 7D) whereas ten segments are identified on the (3 50$)$ mesa. Lateral sides of mesa cut the etched bottom surface to form a lower contour that appears to be composed partly of linear segments and also of curved segments (see Fig. 7B). Successive segments of upper and lower contours form angles denoted $\gamma_{j}$ and $\gamma_{j}^{\prime}$ as defined in Figure 8. With this definition the subscript $j$ increases clockwise. Values for these angles as measured $\left( \pm 1^{\circ}\right)$ on the various diagrams of Figure 7 are listed in Table I. A careful examination of this table shows that experimental values for angles $\gamma_{j}$ and $\gamma_{j}^{\prime}$ satisfy closely the mirror symmetry with respect to the cross-sectional $\left\{\begin{array}{lll}1 & 1 & 0\end{array}\right\}$ plane that cuts the reference plane along the $x_{3}^{\prime}$ axis. So to make easier this observation in Table I corresponding angles are identified by similar superscripts. Moreover an asterisk is assigned to angles whose bisectrix is the $x_{3}^{\prime}$ axis. Corresponding values depart by less than $2^{\circ}$ excepted for the $(350)$ mesa for which a portion of the top contour is jagged. If we compare now values of angles $\gamma_{j}$ and $\gamma_{j}^{\prime}$ it is clear that departures of more than four degrees can only be attributed to the formation beneath the mask of a dissolution profile composed of successive elements with different slopes. All mesa are more and less concerned by such behaviour but in some cases $\left(\begin{array}{lll}1 & 1 & 3\end{array}\right)$
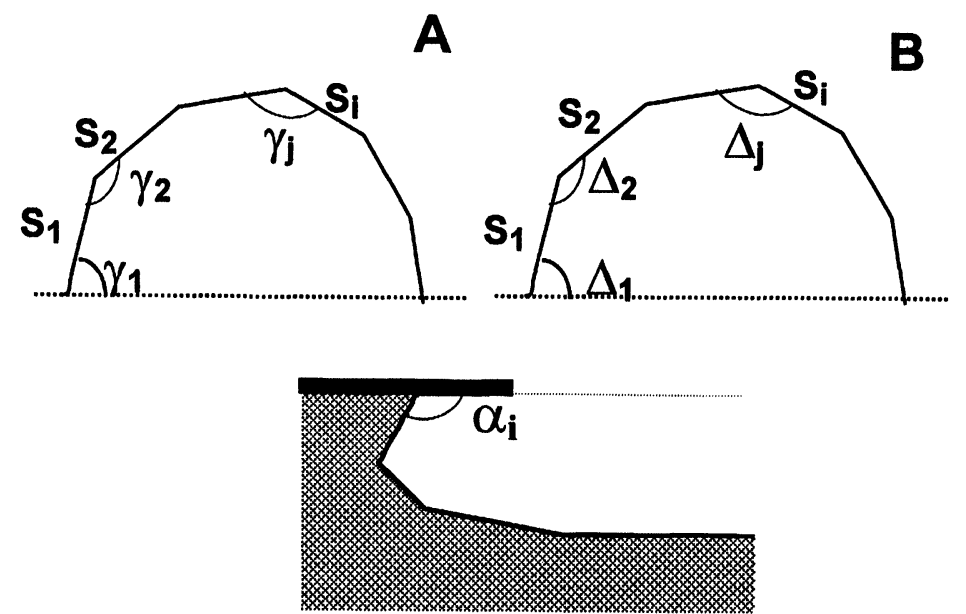

FIGURE 8 Definition of angles and numbering of successive segments for the upper contour of membranes (A) and mesa (B). 
TABLE I Experimental Values (in deg) of Angles $\gamma_{j}$ and $\gamma_{j}^{\prime}$ Formed on the Upper $\left(\gamma_{j}\right)$ and Lower $\left(\gamma_{j}^{\prime}\right)$ Contours of Mesa. CS Denotes a Curved Contour for Which it is Impossible to Define Angles $\gamma_{j}^{\prime}$. ${ }^{* *}$ Correspond to Angles Whose Bisectrix is the $\left\langle\begin{array}{lll}1 & 1 & 0\end{array}\right\rangle$ Direction.

\begin{tabular}{|c|c|c|c|c|c|c|c|}
\hline \multicolumn{2}{|c|}{ (350) mesa } & \multicolumn{2}{|c|}{ (113) mesa } & \multicolumn{2}{|c|}{ (118) mesa } & \multicolumn{2}{|c|}{ (221) mesa } \\
\hline$\gamma_{j}$ & $\gamma_{j}^{\prime}$ & $\gamma_{j}$ & $\gamma_{j}^{\prime}$ & $\gamma_{j}$ & $\gamma_{j}^{\prime}$ & $\gamma_{j}$ & $\gamma_{j}^{\prime}$ \\
\hline $144 * *$ & $144 * *$ & $126^{* * *}$ & $115^{* *}$ & $116^{* *}$ & $118^{* *}$ & $128 * *$ & $125^{* * *}$ \\
\hline $135^{1}$ & $136^{1}$ & $146^{1}$ & $152^{1}$ & $157^{1}$ & $160^{1}$ & $127^{1}$ & $122^{1}$ \\
\hline $144^{2}$ & $142^{2}$ & $146^{2}$ & $147^{2}$ & $141^{2}$ & $140^{2}$ & $161^{2}$ & $162^{2}$ \\
\hline $160^{3}$ & $154^{3}$ & $145^{3}$ & $147^{3}$ & $140^{3}$ & $140^{3}$ & $126^{3}$ & $\mathrm{CS}$ \\
\hline $136^{4}$ & $143^{4}$ & $147^{4}$ & $153^{4}$ & $156^{4}$ & CS & $128 * *$ & $\mathrm{CS}^{* *}$ \\
\hline $144 * *$ & $136 * *$ & $130^{* *}$ & $127 * *$ & $116^{* *}$ & $\mathrm{CS}^{* *}$ & $126^{3}$ & $\mathrm{CS}$ \\
\hline $136^{4}$ & $142^{4}$ & $148^{4}$ & $152^{4}$ & $156^{4}$ & CS & $160^{2}$ & $163^{2}$ \\
\hline $153^{3}$ & $146^{3}$ & $146^{3}$ & $145^{3}$ & $142^{3}$ & $139^{3}$ & $127^{1}$ & $120^{1}$ \\
\hline $148^{2}$ & $147^{2}$ & $146^{2}$ & $146^{2}$ & $140^{2}$ & $140^{2}$ & & \\
\hline $134^{1}$ & $135^{1}$ & $148^{1}$ & $152^{1}$ & $155^{1}$ & $156^{1}$ & & \\
\hline
\end{tabular}

and (2 21 ) mesa for example) this formation is accompanied by the development of a curved lower contour.

In a similar manner sidewalls of membranes cut the upper surface along successive more and less slightly curved segments. Mean values for successive including angles $\delta_{j}$ are reported in Table II. The definition for the angle $\delta_{j}$ is identical to that adopted for the angle $\gamma_{j}$ but owing to the mirror symmetry values are only given for a half contour. In Table II values of $180^{\circ}$ for $(\mathrm{h} h l)$ membranes are associated with the development of $\left\{\begin{array}{lll}1 & 1 & 1\end{array}\right\}$ facets that intersect the reference $(\mathrm{h} h l)$ plane along the $\left\langle\begin{array}{lll}1 & 1 & 0\end{array}\right\rangle$ direction. But as the radius of the circular mask is large compared with the depth of etch they come with curved portions (denoted CS) in the top contour of membranes. It is also difficult to

TABLE II Experimental Values (in deg) of Angles $\delta_{j}$ Formed on the Upper Contours of Membranes. Subscript CS is Given for Angles Resulting from the Intersection of Two Curved Segments.

\begin{tabular}{lll}
\hline (350) membrane & (113) membrane & (118) membrane \\
\hline $180_{\mathrm{CS}}$ & $180_{\mathrm{CS}}$ & $180_{\mathrm{CS}}$ \\
$142_{\mathrm{CS}}$ & $112_{\mathrm{CS}}$ & 138 \\
142 & 145 & 141 \\
143 & 151 & 147 \\
147 & 160 & 145 \\
$150_{\mathrm{CS}}$ & $180_{\mathrm{CS}}$ & $138_{\mathrm{CS}}$ \\
$180_{\mathrm{CS}}$ & & 180 \\
\hline
\end{tabular}


recognise on the contour of Figure 7 short elements that result from the development of sharp edges. It follows from this difficulty and from the formation of curved elements that some angles with subscript CS are given without guarantee. An other consequence is that the mirror symmetry is not totally verified for the (113) membrane. It should be also pointed out that for the $(350)$ membrane angles of $180^{\circ}$ couldn't be attributed to the formation of $\left\{\begin{array}{lll}1 & 1 & 1\end{array}\right\}$ facets. This point will be discussed in the following section.

\subsection{Structures Micromachined in a KOH 56\% Solution}

Complementary experiments on the micromachining of silicon $(\mathrm{h} \mathrm{h} l)$ plates in a $\mathrm{KOH} 56 \%$ solution have been made. Figure 9 shows SEM
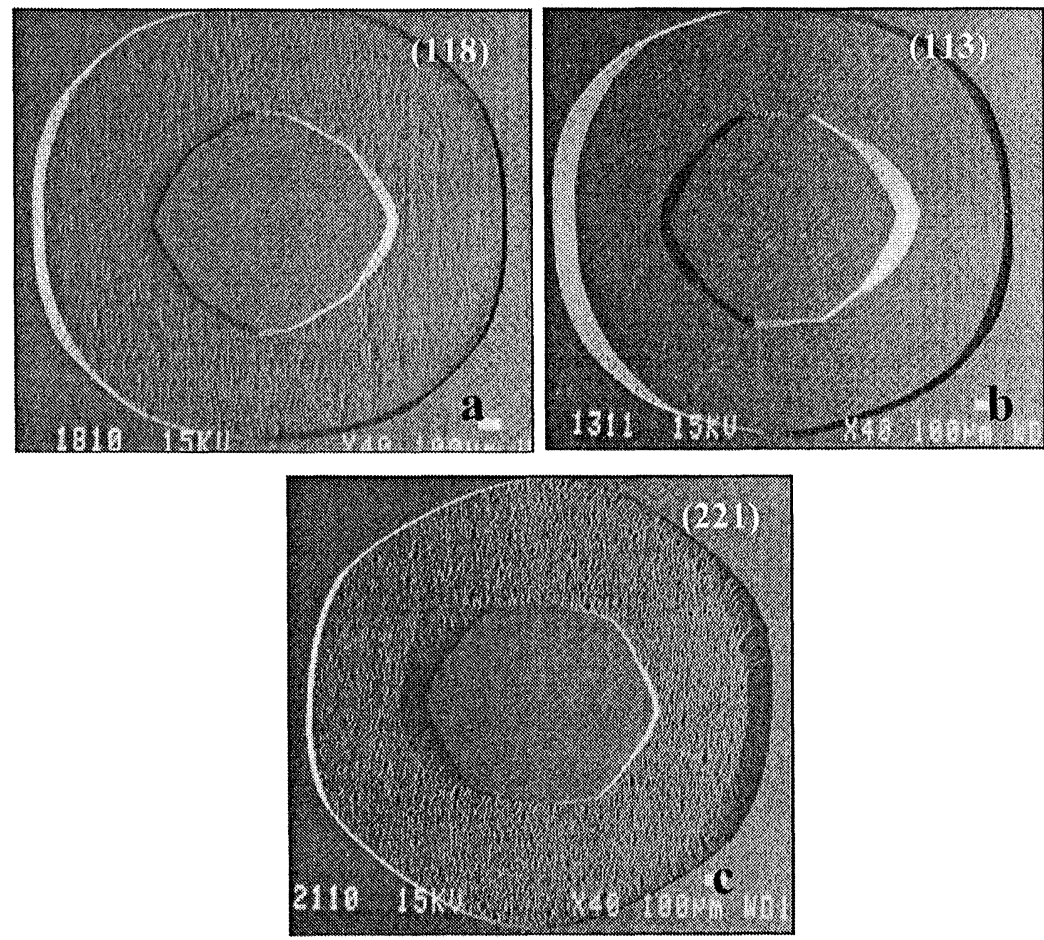

FIGURE 9 SEM images of "circular" ( $\mathrm{h} h l$ ) membrane-mesa structures micromachined in a $\mathrm{KOH} 56 \%$ solution, $\mathbf{a}, \mathbf{b}$ and $\mathbf{c}$ are for (1 18 ), (1113) and (22 21$)$ structures respectively. 
images of "circular" membrane-mesa structures. The comparison of SEM images of Figure 9 with the corresponding SEM images of Figure 4 reveals a very close resemblance in shape. In fact facets limiting membranes and mesa as well as regions where sharp edges develop under the mask are strictly identical. Moreover terraced sidewalls are present on some structures etched in $(\mathrm{h} h l)$ plates. Such a behaviour and be also depicted on structures etched in a $\mathrm{NaOH} 35 \%$ solution (Compare Figs. 9b and 9c with Figs. $4 \mathrm{~b}$ and $4 \mathrm{c}$ for example).

If we put attention to the geometrical features of etched surfaces we observe that the degradation of surfaces induced by prolonged etching is more marked for $(\mathrm{h} h l)$ plates than for (1 111$)$ plates in complete agreement with results reported in the part 1 of this paper. It is also important to outline that dissolution figures that develop on $(\mathrm{h} h l)$ plates etched in a $\mathrm{KOH} 56 \%$ solution are similar to those caused by a chemical attack in the $\mathrm{NaOH} 35 \%$ etchant.

\section{ANALYSIS AND DISCUSSION}

\subsection{The Stereographic Analysis}

The stereographic representation can be used to analyse the final shape of 3D structures $[12,13,19]$ and specially to identify facets limiting membranes and mesa. In the past few years tentative to determine the limiting planes has been made for simple structures etched in (100) or (1 10$)$ planes $[12,13]$. In the following the method is applied to (h $\mathrm{k} 0)$ and $(\mathrm{h} h l)$ reference planes which are singly or doubly rotated cuts with angles of cut $\varphi_{\mathrm{o}}$ and $\left(\varphi_{\mathrm{o}}, \theta_{\mathrm{o}}\right)$ respectively.

At this point it seems of interest to recall the basis of the method. Let be $n\left(\left(\varphi_{F}, \theta_{F}\right)\right.$ the outward unit normal to a doubly rotated plate (corresponding to a given $(\mathrm{h} \mathrm{k} l)$ plane with angles of cut $\left(\varphi_{F}, \theta_{F}\right)$ ) that is supposed to be a limiting facet $F$. The reference plate of cut $\left(\varphi_{\mathrm{o}}, \theta_{\mathrm{o}}\right)$ with an outward normal $n\left(\varphi_{\mathrm{o}}, \theta_{\mathrm{o}}\right)$ serves as a projection plane $\mathcal{P}_{\mathrm{o}}$ in the stereographic representation (Fig. 10) The facet $F\left(\varphi_{F}, \theta_{F}\right)$ is represented on the sphere by a point $P_{F}$ and by a point $H_{F}$ on the projection plane. The point $H_{F}$ corresponds to the intersection of the segment that connects the south pole $S$ to the point $P_{F}$ with the projection plane $\mathcal{P}_{\mathrm{o}}$. We have to keep in mind that the stereographic projection has the following properties: 


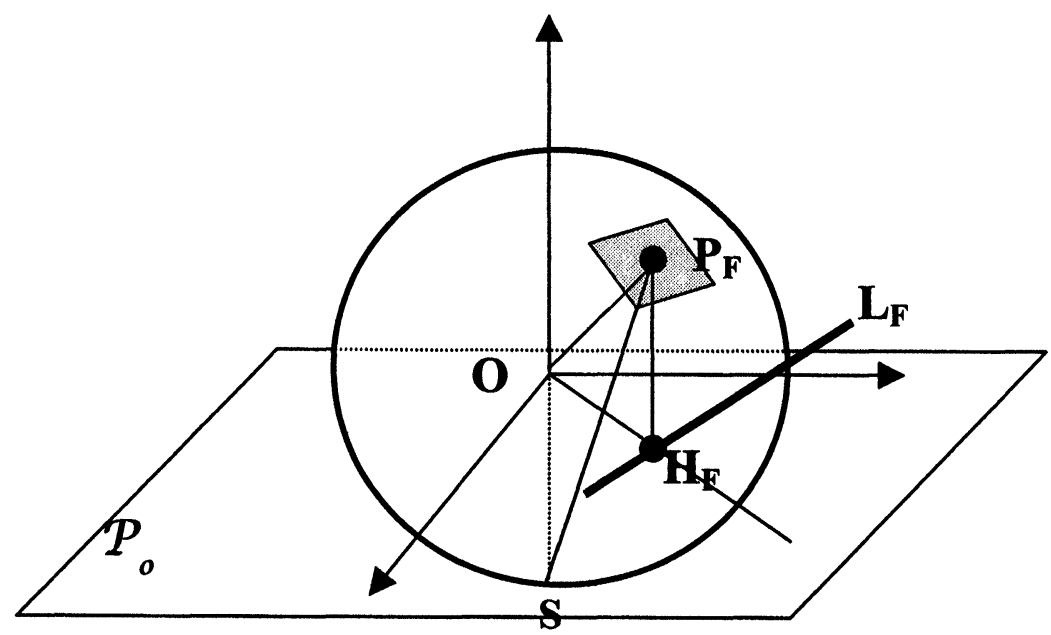

FIGURE 10 The stereographic projection.

(a) The intersection of a facet $F$ with the projection plane is a straight line that lies perpendicular to the segment $\mathrm{OH}_{F}$.

(b) The stereographic projection leaves all angles unchanged.

As a consequence a stereographic projection of limiting facets that gives the successive intersecting lines $L_{\mathrm{Fi}}$ of these facets with the upper and lower surfaces will allow us to construct approximate top contours of mesa and membranes as viewed on SEM images and constantlevel contour diagrams.

\subsection{Analysis for Mesa}

Limiting facets $F_{i}$ with inclination $\alpha_{i}$ cut the upper surface of mesa along linear segments $S_{i}$. Two successive segments of the top contour form an angle $\gamma_{j}$. When we move clockwise on the top contour of the mesa, angles $\gamma_{j}$ and segments $S_{i}$ are referred alphabetically and by increasing numbers respectively. Only half values are given for some angles (with an asterisk as superscript) owing to the mirror symmetry of the etched structure.

At this point let us recall that in the first part of the paper $\begin{cases}113 & 3\end{cases}$ planes have been identified as planes probably associated with minima in the dissolution slowness. So in the following attempts were made to 
highlight the role played by $\left\{\begin{array}{lll}1 & 1 & 3\end{array}\right\}$ planes in the convex corner undercutting and to detect an eventual participation of other limiting planes to membranes.

With this aim consider the (350) mesa for which five intersecting lines can be identified on the SEM image (Fig. 3) and on the constant level contour diagram (Fig. 7D). Assuming that a priori $\left\{\begin{array}{lll}1 & 13\end{array}\right\}$ facets surround the $(350)$ mesa the stereographic projection of the $\left\{\begin{array}{lll}1 & 13\end{array}\right\}$ facets on the $(350)$ plane allows us to construct the top contour of Figure 10D. On this figure the intersecting segments 2 and 3 associated with limiting planes forming a sharp edge are drawn in dotted lines. Theoretical and experimental values for angles $\gamma_{j}$ (denoted by $a^{*}$ to $\left.f^{*}\right)$ are reported in the Table III. Limiting $\left\{\begin{array}{lll}1 & 1 & 3\end{array}\right\}$ planes are identified and in addition their inclination are also listed in this table. Comparison of experimental and theoretical values for angles $\gamma_{j}$ show a satisfactory agreement so that we estimate that the top contour of the $(350)$ mesa is primarily determined by limiting $\{113\}$ facets.

Note that two possible limiting $\left\{\begin{array}{lll}1 & 1 & 3\end{array}\right\}$ planes can be associated with the segment 5 :

(i) Firstly the plane $(\overline{3} 11)$ with an inward normal (Fig. 12) and an inclination close to $102^{\circ}$

(ii) Secondly the (1 31 l) plane with an outward normal and an inclination of about $52^{\circ}$ For these two planes the angle $f^{*}$ takes close values $\left(72^{\circ}\right.$ and $67.4^{\circ}$ respectively) which remain in the domain of the experimental errors essentially because regions of mesa contour related to inward plane cannot be perfectly restored by a mechanical profilometer.

TABLE III Analysis of the Etching Shape for a (350) Mesa. Theoretical and Experimental Values of Angles $\gamma_{j}(\mathrm{deg})$ as Referenced Alphabetically on Figure 8. Identification of $\left\{\begin{array}{lll}1 & 1 & 3\end{array}\right\}$ Facets Forming the Top Contour and Their Inclination $\alpha_{i}(\mathrm{deg})$ with Respect to the $(350)$ Surface.

\begin{tabular}{|c|c|c|c|c|c|}
\hline$\gamma_{j}(\mathrm{deg})$ & Theory & Experiment & No. & Plane $\left\{\begin{array}{lll}1 & 1 & 3\end{array}\right\}$ & $\alpha_{i}(\operatorname{deg})$ \\
\hline$a^{*}$ & 72.05 & 72 & 1 & $(3 \overline{1} 1)$ & 78.06 \\
\hline b & 132.5 & 135 & 2 & $(1 \overline{1} 3)$ & 95.93 \\
\hline c & 148.93 & 144 & 3 & $(\overline{1} \overline{1} 3)$ & 114.45 \\
\hline $\mathrm{d}$ & 161.93 & 160 & 4 & $\left(\begin{array}{lll}1 & 1 & 3\end{array}\right)$ & 84.06 \\
\hline e & 137.18 & 136 & 5 & $(\overline{3} 11)$ & 101.94 \\
\hline $\mathrm{f}^{*}$ & 72.05 & 72 & & & \\
\hline
\end{tabular}



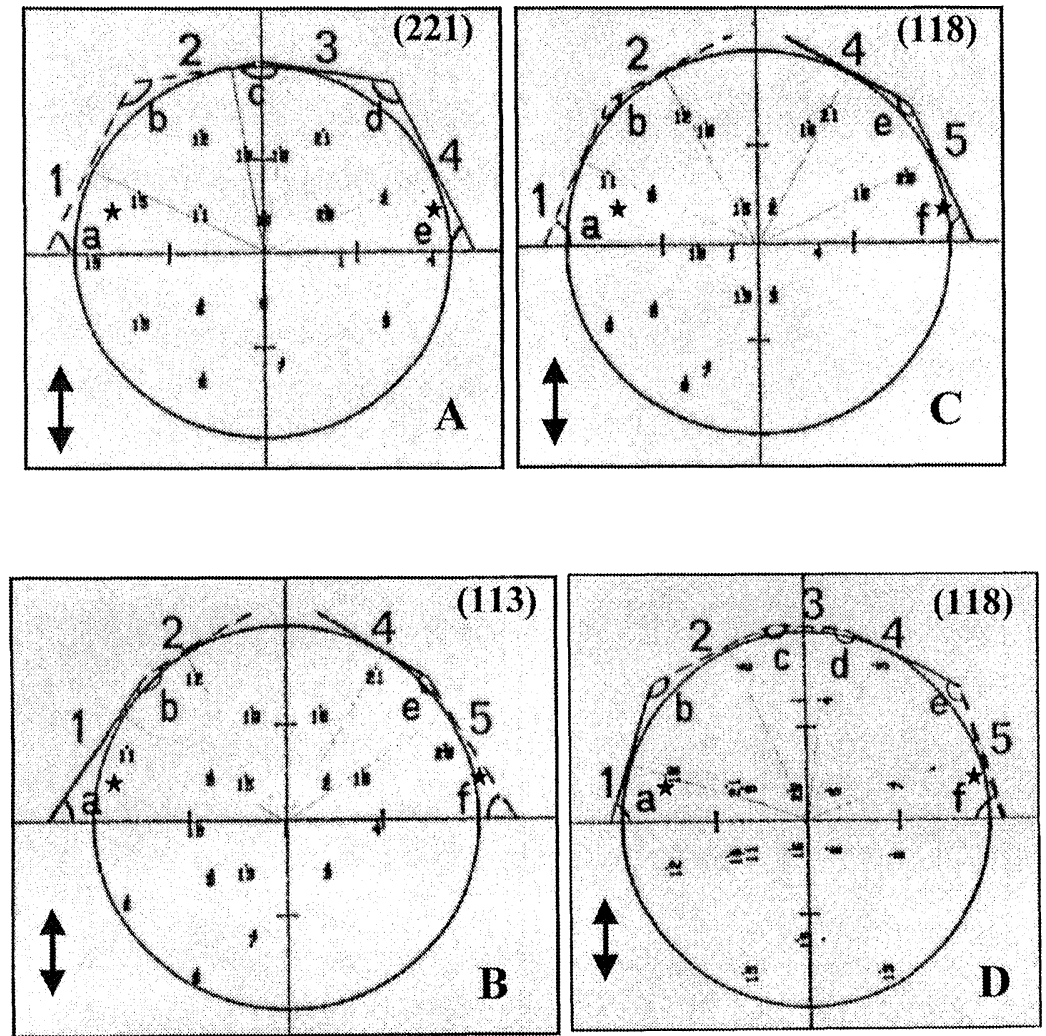

FIGURE 11 The top contour for various "circular" ( $\mathrm{h} \mathrm{h} l)$ or $(\mathrm{h} \mathrm{k} 0)$ mesa as derived from the stereographic analysis. A, B, C and D are for (2 21 1), (1 113$),\left(\begin{array}{lll}1 & 1 & 8\end{array}\right)$ and (3 50 ) structures respectively.
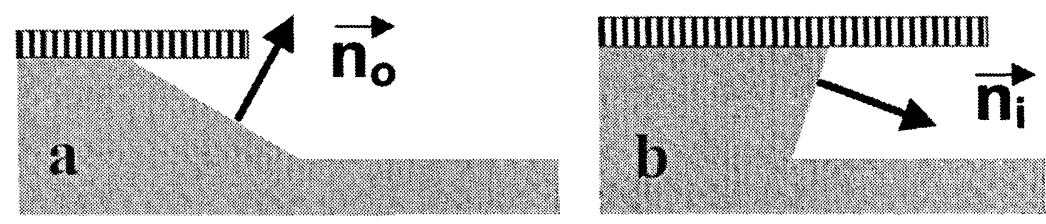

FIGURE 12 Definition of outward (a) and inward (b) normal and facet. 
Similar analyses are performed for the (1 118$),\left(\begin{array}{lll}1 & 1 & 3\end{array}\right)$ and (2 211$)$ mesa. Tables IV to VI summarise the main results. Several features emerge from these tables:

(1) Most of limiting facets that contribute to the top contour of $(\mathrm{h} \mathrm{h} l)$ mesa correspond also two by two to projection points symmetrical

TABLE IV Analysis of the Etching Shape for a (118) Mesa. Theoretical and Experimental Values of Angles $\gamma_{j}(\mathrm{deg})$ as Referenced Alphabetically on Figure 8. Identification of $\left\{\begin{array}{lll}1 & 1 & 3\end{array}\right\}$ Facets Forming the Top Contour and Their Inclination $\alpha_{1}$, (deg) with Respect to the (1 118$)$ Surface. Note that One Plane was not Identified as an (1 113$)$ Plane Resulting in no Consecutive Reference Numbers and Alphabetical References.

\begin{tabular}{lrcccr}
\hline$\gamma_{j}(\mathrm{deg})$ & Theory & Experiment & No. & Plane $\{113\}$ & $\alpha_{i}(\mathrm{deg})$ \\
\hline a* & 64.46 & 63 & 1 & $(31 \overline{1})$ & 98.53 \\
$\mathrm{~b}$ & 144.62 & 146 & 2 & $(3 \overline{1} \overline{1})$ & 102.87 \\
- & - & - & 4 & $(1 \overline{3} 1)$ & 77.13 \\
$\mathrm{e}$ & 144.62 & 147 & 5 & $(\overline{1} \overline{3} 1)$ & 81.46 \\
$\mathrm{f}^{*}$ & 64.46 & 65 & & & \\
\hline
\end{tabular}

TABLE V Analysis of the Etching Shape for a (113) Mesa. Theoretical and Experimental Values of Angles $\gamma_{j}(\mathrm{deg})$ as Referenced Alphabetically on Figure 8. Identification of $\left\{\begin{array}{lll}1 & 1 & 3\end{array}\right\}$ Facets Forming the Top Contour and their Inclination $\alpha_{i}(\mathrm{deg})$ with Respect to the (1 113$)$ Surface. Note that One Plane was not Identified as an $\left\{\begin{array}{lll}1 & 1 & 3\end{array}\right\}$ Plane Resulting in No Consecutive Reference Numbers and Alphabetical References.

\begin{tabular}{lrcccr}
\hline$\gamma_{j}(\mathrm{deg})$ & Theory & Experiment & No. & Plane $\{113\}$ & $\alpha_{i}(\operatorname{deg})$ \\
\hline $\mathrm{a}^{*}$ & 56.44 & 58 & 1 & $(31 \overline{1})$ & 50.47 \\
$\mathrm{~b}$ & 154.65 & 157 & 2 & $(3 \overline{1} \overline{1})$ & 95.21 \\
- & - & - & 4 & $(1 \overline{3} 1)$ & 84.78 \\
$\mathrm{e}$ & 154.65 & 156 & 5 & $(\overline{1} \overline{3} \overline{1})$ & 129.52 \\
$\mathrm{f}^{*}$ & 56.44 & 58 & & & \\
\hline
\end{tabular}

TABLE VI Analysis of the Etching Shape for a (221) Mesa. Theoretical and Experimental Values of Angles $\gamma_{j}(\mathrm{deg})$ as Referenced Alphabetically on Figure 8 Identification of $\left\{\begin{array}{llll}1 & 1 & 3\end{array}\right\}$ Facets Forming the Top Contour and Their Inclination $\alpha_{i}(\mathrm{deg})$ with Respect to the $(221)$ Surface.

\begin{tabular}{lrcccr}
\hline$\gamma_{j}(\mathrm{deg})$ & Theory & Experiment & No. & Plane $\{113\}$ & $\alpha_{i}(\mathrm{deg})$ \\
\hline a* & 63.44 & 64 & 1 & $(1 \overline{1} \overline{3})$ & 107.55 \\
$\mathrm{~b}$ & 126.03 & 127 & 2 & $(1 \overline{3} \overline{1})$ & 120.16 \\
$\mathrm{c}$ & 161.06 & 161 & 3 & $(3 \overline{1} 1)$ & 59.83 \\
$\mathrm{~d}$ & 126.03 & 126 & 4 & $(1 \overline{1} 3)$ & 72.45 \\
$\mathrm{e}^{*}$ & 63.44 & 64 & & & \\
\hline
\end{tabular}


with respect to the vertical axis of the stereographic projection. One of limiting facets has an outward normal and the other an inward normal (compare for example facet 5 with facet 1 in tables related to (1 118$)$ and (1 113$)$ mesa).

(2) For the (118) mesa it can't be possible to identify all facets bounding mesa. In particular the facet that cuts the upper surface along a nearly horizontal element is not due to a $\left\{\begin{array}{lll}1 & 1 & 3\end{array}\right\}$ facet. At this point let us recall that in the first part of this paper we concluded that, for the $\mathrm{NaOH} 35 \%$ etchant, $\left\{\begin{array}{lll}1 & 1 & 0\end{array}\right\}$ planes in contrast with other etchants $[2,8,9]$ are not associated with protuberances of the dissolution slowness surface and that the $\left\{\begin{array}{lll}1 & 1 & 0\end{array}\right\}$ planes dissolve rapidly [10]. Consequently it is reasonable to argue in
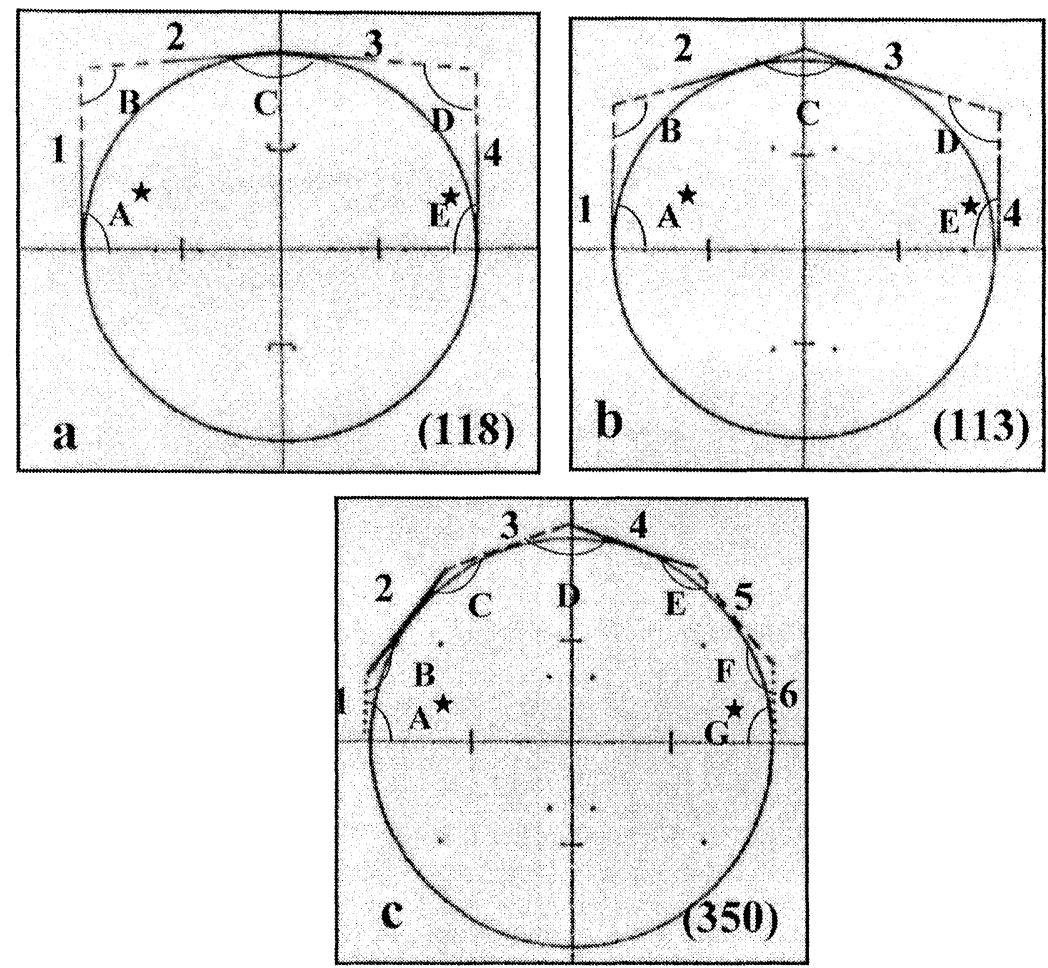

FIGURE 13 The top contour for various "circular" (h $\mathrm{h} l$ ) or (h $\mathrm{k} 0$ ) membranes as derived from the stereographic analysis, a, b and $\mathbf{c}$ are for (113), (118) and (350) structures respectively. 
favour of a possible participation of some $\left\{\begin{array}{lll}1 & 1 & 0\end{array}\right\}$ planes to mesa. It seems of interest in this case to investigate the possibility of a

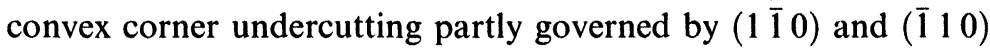
planes. The fact that these planes are perpendicular to the $(\mathrm{h} h l)$ reference plane agrees well with experimental observations that speak for a formation of a facet with a steep slope (see SEM images of Fig. 4). The participation of these $\left\{\begin{array}{lll}1 & 10 & 0\end{array}\right.$ facets to the (22 1) mesa seems also possible but cannot be easily detected on the SEM image of Figure 4c.

(3) Most of theoretical contours (portion or total contour) as derived from the stereographic projection fit well the experimental $(\mathrm{h} h l)$ contours. Nevertheless the agreement between theoretical and experimental values for angles $\gamma_{j}$ and $\alpha_{i}$ seems very satisfactory. In this condition we can infer that $\left\{\begin{array}{lll}1 & 1 & 3\end{array}\right\}$ facets limit $(\mathrm{h} h l)$ mesa and that these $\left\{\begin{array}{lll}1 & 1 & 3\end{array}\right\}$ facets are associated with relatively deep valleys of the dissolution slowness surface.

\subsection{Analysis for Membranes}

For the $(\mathrm{h} h l)$ membranes we have decided to draw the stereographic contour resulting only from the development of $\left\{\begin{array}{lll}1 & 1 & 1\end{array}\right\}$ limiting facets. In this condition in the one hand, some elements of the contour may be forgotten in regions that are distinguished on theoretical contours by dashed lines, and in the second hand, angles $\Delta_{j}$ formed by two successive elements can differ markedly from angles $\delta_{j}$ measured on the experimental top contours. At this point it should be noticed that forgotten regions might be due:

(i) Firstly, to the contribution of other planes associated with minor protuberances of the dissolution slowness surface. This occurs for some typical orientations of the reference plane.

(ii) Secondly, to the formation of curved boundaries and top contours. Effectively the initial radius of the circular mask is finite $(=1000 \mu \mathrm{m})$ and consequently the disappearance of some surface element may take a long time.

Definition of angles and the method to number limiting facets are given in Figure 8B. Tables VII to IX indicate a good concordance 
TABLE VII Analysis of the Etching Shape for a (350) Membrane. Theoretical and Experimental Values of Angles $\Delta_{j}(\mathrm{deg})$ as Referenced Alphabetically on Figure 8 where

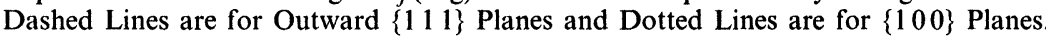
Identification of $\left\{\begin{array}{lll}1 & 1 & 1\end{array}\right\}$ Facets Forming the Top Contour and Their Inclination $\alpha_{i}(\mathrm{deg})$ with Respect to the (350) Surface.

\begin{tabular}{|c|c|c|c|c|c|}
\hline$\Delta_{j}$ & Theory & Experiment & No. & $F_{j}$ & $\alpha_{j}$ \\
\hline$A^{*}$ & 90 & $90_{\mathrm{CS}}$ & 1 & $\left(\begin{array}{lll}1 & 0 & 0\end{array}\right)$ & 59.04 \\
\hline B & 143.91 & 142 & 2 & $(\overline{1} 1 \overline{1})$ & 78.58 \\
\hline C & 144.98 & 142 & 3 & $(\overline{1} \overline{1} \overline{1})$ & 142.38 \\
\hline D & 142.12 & 143 & 4 & $(111 \overline{1})$ & 37.61 \\
\hline $\mathrm{E}$ & 144.48 & 147 & 5 & $(1 \overline{1} \overline{1})$ & 101.42 \\
\hline $\mathbf{F}$ & 143.91 & $150_{\mathrm{CS}}$ & 6 & $\begin{array}{l}\left(\begin{array}{lll}0 & 1 & 0\end{array}\right) \\
\left(\begin{array}{lll}1 & 0 & 0\end{array}\right)\end{array}$ & $\begin{array}{r}30.96 \\
120.96\end{array}$ \\
\hline $\mathrm{G}^{*}$ & 90 & $90_{\mathrm{CS}}$ & & & \\
\hline
\end{tabular}

TABLE VIII Analysis of the Etching Shape for a (118) Membrane. Theoretical and Experimental Values of Angles $\Delta_{j}(\mathrm{deg})$ as Referenced Alphabetically on Figure 8. Identification of $\left\{\begin{array}{lll}1 & 1 & 1\end{array}\right\}$ Facets Forming the Top Contour and Their Inclination $\alpha_{i}(\mathrm{deg})$ with Respect to the (1 18$)$ Surface.

\begin{tabular}{|c|c|c|c|c|c|}
\hline$\Delta_{j}$ & Theory & Experiment & No. & $F_{j}$ & $\alpha_{j}$ \\
\hline$A^{*}$ & 90 & 90 & 1 & $\left(\begin{array}{lll}1 & 1 & 1\end{array}\right)$ & 44.71 \\
\hline B & 97.02 & 98 & 2 & $(1 \overline{1} \overline{1})$ & 124.65 \\
\hline $\mathrm{C}$ & 159.94 & 157 & 3 & $(1 \overline{1} 1)$ & 55.35 \\
\hline D & 97.02 & 98 & 4 & $(\overline{1} \overline{1} 1)$ & 64.96 \\
\hline$E^{*}$ & 90 & 90 & & & \\
\hline
\end{tabular}

TABLE IX Analysis of the Etching Shape for a (113) Membrane. Theoretical and Experimental Values of Angles $\Delta_{j}(\mathrm{deg})$ as Referenced Alphabetically on Figure 8. Identification of $\left\{\begin{array}{lll}1 & 1 & 1\end{array}\right\}$ Facets Forming the Top Contour and Their Inclination $\alpha_{i}(\mathrm{deg})$ with Respect to the (1 113$)$ Surface.

\begin{tabular}{|c|c|c|c|c|c|}
\hline$\Delta_{j}$ & Theory & Experiment & No. & $F_{j}$ & $\alpha_{j}$ \\
\hline$A^{*}$ & 90 & $90_{\mathrm{CS}}$ & 1 & $\left(\begin{array}{lll}1 & 1 & 1\end{array}\right)$ & 29.49 \\
\hline B & 106.78 & 108 & 2 & $(1 \overline{1} \overline{1})$ & 121.48 \\
\hline $\mathrm{C}$ & 145.4 & 145 & 3 & (111) & 58.51 \\
\hline $\mathrm{D}$ & 106.78 & 108 & 4 & $\left(\begin{array}{lll}1 & 1 & 1\end{array}\right)$ & $\begin{array}{r}79.97 \\
150.5\end{array}$ \\
\hline$E^{*}$ & 90 & $90_{\mathrm{CS}}$ & & & \\
\hline
\end{tabular}

between theoretical and experimental values of angles $\Delta_{j}$ allowing us to recognise the various $\left\{\begin{array}{lll}1 & 1 & 1\end{array}\right\}$ planes limiting the $(\mathrm{h} h l)$ membranes. Results for the (350) membrane appear to be less satisfactory but we have to keep in mind that the experimental contour is partly jagged. Moreover in Table VII we have also made some tentative to identify 
facets 1 and 6. At this point it becomes necessary to note that for the (3 50) membrane the vertical axis coincides with the [0 011$]$ axis so the two segments correspond certainly to intersections of $\left\{\begin{array}{lll}1 & 0 & 0\end{array}\right\}$ limiting planes with the $(350)$ plane. Effectively a previous work has shown that $\left\{\begin{array}{lll}1 & 0 & 0\end{array}\right\}$ planes are associated with protuberances of the dissolution slowness surface. So in terms of dissolution criteria $\left\{\begin{array}{lll}1 & 0 & 0\end{array}\right\}$ facets can limit (h k 0) membranes. In fact for the segment 6 a rapid geometrical construction speaks for a dissolution profile composed of two intersecting $\left\{\begin{array}{lll}1 & 0 & 0\end{array}\right\}$ planes that form a sharp edge beneath the mask.

\subsection{Discussion}

The stereographic analysis gives clearly evidence for the active participation of $\left\{\begin{array}{lll}1 & 1 & 3\end{array}\right\}$ facets to mesa. So as noticed in part I of this paper, $\left\{\begin{array}{lll}1 & 1 & 3\end{array}\right\}$ planes are associated with relatively deep valleys of the dissolution slowness surface (i.e. with small minima in the dissolution slowness). Moreover this analysis speaks also for a possible formation of $\left\{\begin{array}{lll}1 & 1 & 0\end{array}\right\}$ facets that limit partly mesa. This interpretation agrees well a previous conclusion [10] in which we suggested that $\left\{\begin{array}{lll}1 & 1 & 0\end{array}\right\}$ planes be not connected with maxima in the dissolution slowness as observed for other etchants $[8,9]$.

From the experimental study and from the stereographic analysis we can conclude that the anisotropy of the chemical attack of the silicon crystal in a $\mathrm{NaOH} 35 \%$ solution is of type 1. This anisotropy is characterised by the existence of very prolate protuberances in the dissolution slowness surface (related to $\left\{\begin{array}{lll}1 & 1 & 1\end{array}\right\}$ planes) together with the simultaneous presence of minima that all are smaller than the smallest maximum in the dissolution slowness. Such a dissolution process can be described at the micrometer scale by the kinematic and tensorial model of the anisotropic dissolution proposed several years ago by Tellier et al. [21,22] and from which a numerical simulation of 2D and 3D etching shapes called TENSOSIM is originated.

\section{CONCLUSION}

Final etching shapes of membrane-mesa structures micromachined in various $\{\mathrm{hk} 0\}$ and $\{\mathrm{h} h l\}$ planes were systematically investigated. This 
study reveals that the 3D etching shapes show a marked anisotropy of type 1. Planes connected with the protuberances of the dissolution slowness surface bound membranes. In particular $\left\{\begin{array}{llll}1 & 1 & 1\end{array}\right\}$ planes that are related to the eight prolate protuberances of the slowness surface participate in majority to etched membranes. In contrast planes that dissolve more rapidly limit mesa. These observations verify the dissolution criteria as stated by Irving [20].

In addition a stereographic analysis of top contours and membrane and mesa was performed. This analysis confirms that as expected $\left\{\begin{array}{lll}1 & 1 & 1\end{array}\right\}$ planes contribute to all membranes whereas the participation of $\left\{\begin{array}{lll}1 & 0 & 0\end{array}\right\}$ remains occasional. For mesa a close agreement is observed between experimental and theoretical contour shapes derived from stereographic projections as obtained by assuming that $\left\{\begin{array}{lll}1 & 1 & 3\end{array}\right\}$ facets bound mesa. So $\left\{\begin{array}{lll}1 & 1 & 3\end{array}\right\}$ planes are surely associated with valleys of the dissolution slowness surface. However other planes limit also mesa. It is suggested that $\left\{\begin{array}{lll}1 & 1 & 0\end{array}\right\}$ planes can also contribute to mesa. This assumption agrees well with a previous work devoted to $2 \mathrm{D}$ etching shapes [10].

In conclusion, by combining a stereographic analysis of etched contours and a tensorial and kinematic analysis of $3 \mathrm{D}$ etching shapes based on dissolution criteria it is possible to identify crystallographic planes related to maxima and minima in the dissolution slowness surface. These results are of prime importance for the adjustment of the dissolution constants that compose the database of the simulator TENSOSIM $[8,9,15,18]$. Attempts will be made in a future paper to compare theoretical 2D etching shapes as derived from the simulator with experimental shapes.

\section{References}

[1] Petersen, K. E. (1982). Silicon as a mechanical material. Proc. IEEE, 70, 420-457.

[2] Schnakenberg, U., Benecke, W. and Lochel, B. B. (1990). $\mathrm{NH}_{4} \mathrm{OH}$-based etchants for silicon micromachining. Sensors and Actuators A, 21-23, 1031-1035.

[3] Kaminsky, G. (1985). Micromachining of silicon mechanical structures. J. Vac. Sci. Technol. B, 3, 1015-1024.

[4] Kanda, Y. (1991). Piezoresistance effect of silicon. Sensors and Actuators A, 28, 8392.

[5] Durand, S. and Tellier, C. R. (1996). Linear and non-linear piezoresistance coefficients in cubic semiconductors. I. Theoretical formulations. J. Phys. III France, 6, 237-266. 
[6] Charbonnieras, A. R. and Tellier, C. R. (1999). A kinetic formulation of piezoresistance in N-type silicon: Application to non-linear effects. Eur. Phys. J., AP-7, 1-11.

[7] (1978). IEEE Standard on Piezoelectricity. IEEE, New York, p. 15.

[8] Tellier, C. R. and Durand, S. (1997). Micromachining of ( $\mathrm{h} \mathrm{hl}$ ) structures: Experiments and 3D simulation of etched shapes. Sensors and Actuators A, 60, 168-175.

[9] Tellier, C. R., Charbonnieras, A. and Hodebourg, C. (2001). Simulation of etching shapes for $\{\mathrm{h} h l\}$ structures micromachined in a TMAH $25 \%$ solution. Sensor 2001 , May 8-10, 2001, AMA Service GmbH Publisher, Nuremberg, Germany, pp. 269274.

[10] Hodebourg, C. A., and Tellier, C. R. (2001). Some investigations on the anisotropy of the chemical etching of $(\mathrm{h} \mathrm{k} 0)$ and $(\mathrm{h} \mathrm{h} l)$ silicon plates in a $\mathrm{NaOH} 35 \%$ solution. Part I: 2D etching shapes. Active and Passive Elec. Comp., pp. 1-25 (in press).

[11] Puers, B. and Sansen, A. (1990). Compensation structures for convex corner micromachining in silicon. Sensors and Actuators A, A21-A23, 1036-1041.

[12] Zubel, I. and Barycka, I. Silicon anisotropic etching in alkaline solutions $\mathbf{I}$. The geometric description of figures developed under etching $\mathrm{Si}(100)$ in various solutions. Sensors and Actuators A, 70, 250-259.

[13] Barycka, I. and Zubel, I. (1995). Silicon anisotropic etching in $\mathrm{KOH}$-isopropanol etchant. Sensors and Actuators A, 48, 229-238.

[14] Tellier, C. R., Messaoudi, T., Leblois, T. G. and Durand, S. (1997). Convex and concave undercutting in the micromachining of quartz and silicon mechanical structures. 11th European Frequency and Time Forum, March 8-11, 1997, Neufchatel, Switzerland, FSRM Publisher, Neuchâtel, pp. 386-390.

[15] Tellier, C. R., Amaudrut, J. Y. and Brahim-Bounab, A. (1991). The dissolution slowness of cubic crystals: Part II: Applications to class 23 and to combined etching and lithography techniques. J. Mater. Sci., 26, 5595-5607.

[16] Csepregi, L. (1985). Micromechanics: A silicon fabrication technology. Microelectronic Engineering, 3, 221-234.

[17] Wu, X.-P. and Ko, W. H. (1989). Compensating corner undercutting in anisotropic etching of (100) silicon. Sensors and Actuators, 18, 207-215.

[18] Tellier, C. R. (1998). Anisotropic etching of silicon crystals in $\mathrm{KOH}$ solution. Part III. Experimental and theoretical shapes for 3D structures micromachined in (h k 0) plates. J. Mater. Sci., 33, 117-131.

[19] Tellier, C. R. and Leblois, T. G. (1999). Some applications of a stereographic analysis of etching shapes for structures micromachined in singly and doubly rotated quartz plates. IEEE International Frequency Control Symposium, April 1316, 1998, IEEE, Besançon, France, pp. 847-850.

[20] Irving, B. A. (1962). In: Holmes, P. J. (Eds.), The Electrochemistry of Semiconductors. Academic Press, London, pp. 262-294.

[21] Tellier, C. R. (1989). A three-dimensional kinematic model for the dissolution of crystals. J. Cryst. Grow'th, 96, 450-452.

[22] Tellier, C. R. (1988). Micro-usinage Chimique du Quartz: Modélisation et Contrôle par Microscopie Electronique à Balayage. Rapport DRET, Convention 85.34.099.470.75.01, Février, pp. 169. 

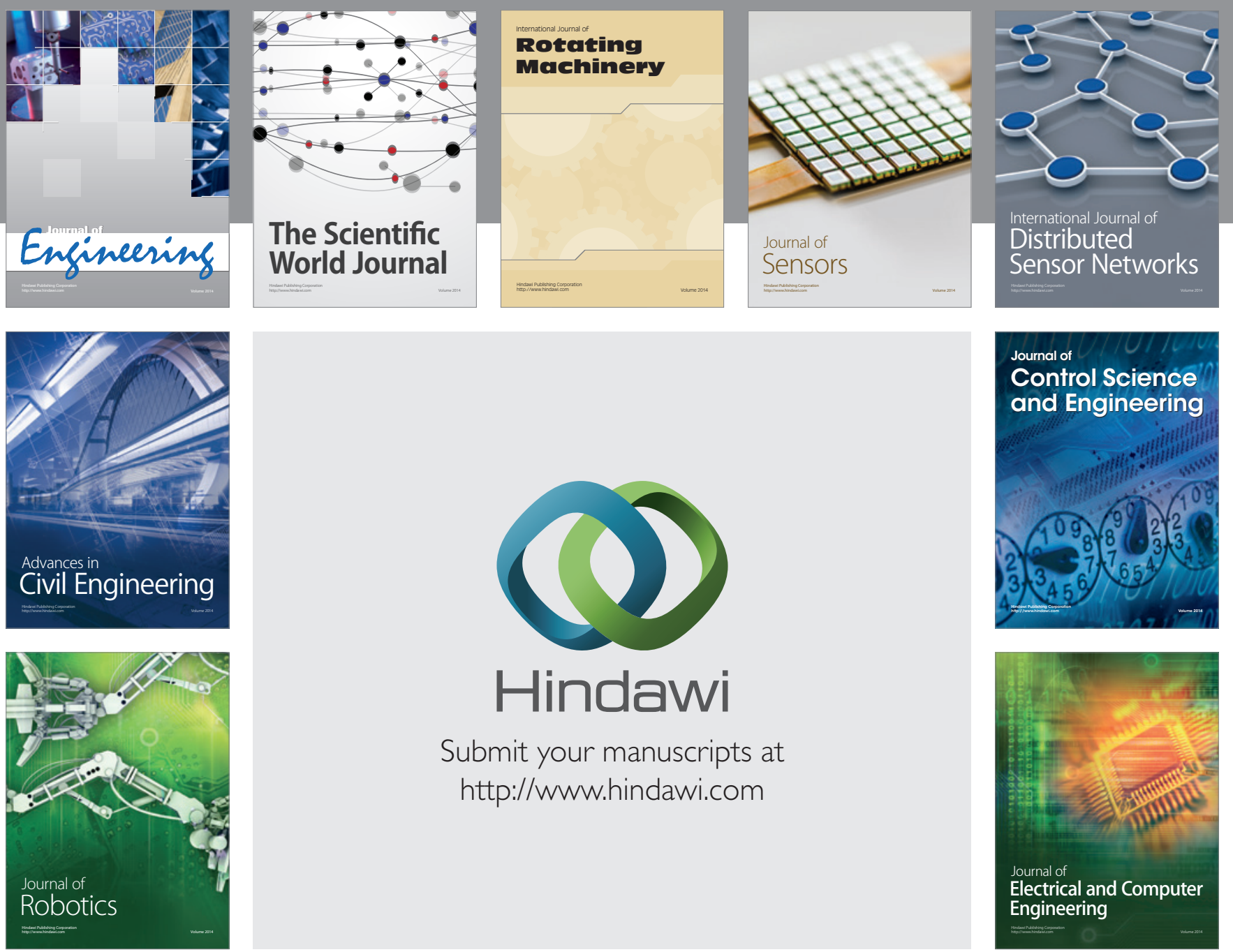

Submit your manuscripts at

http://www.hindawi.com
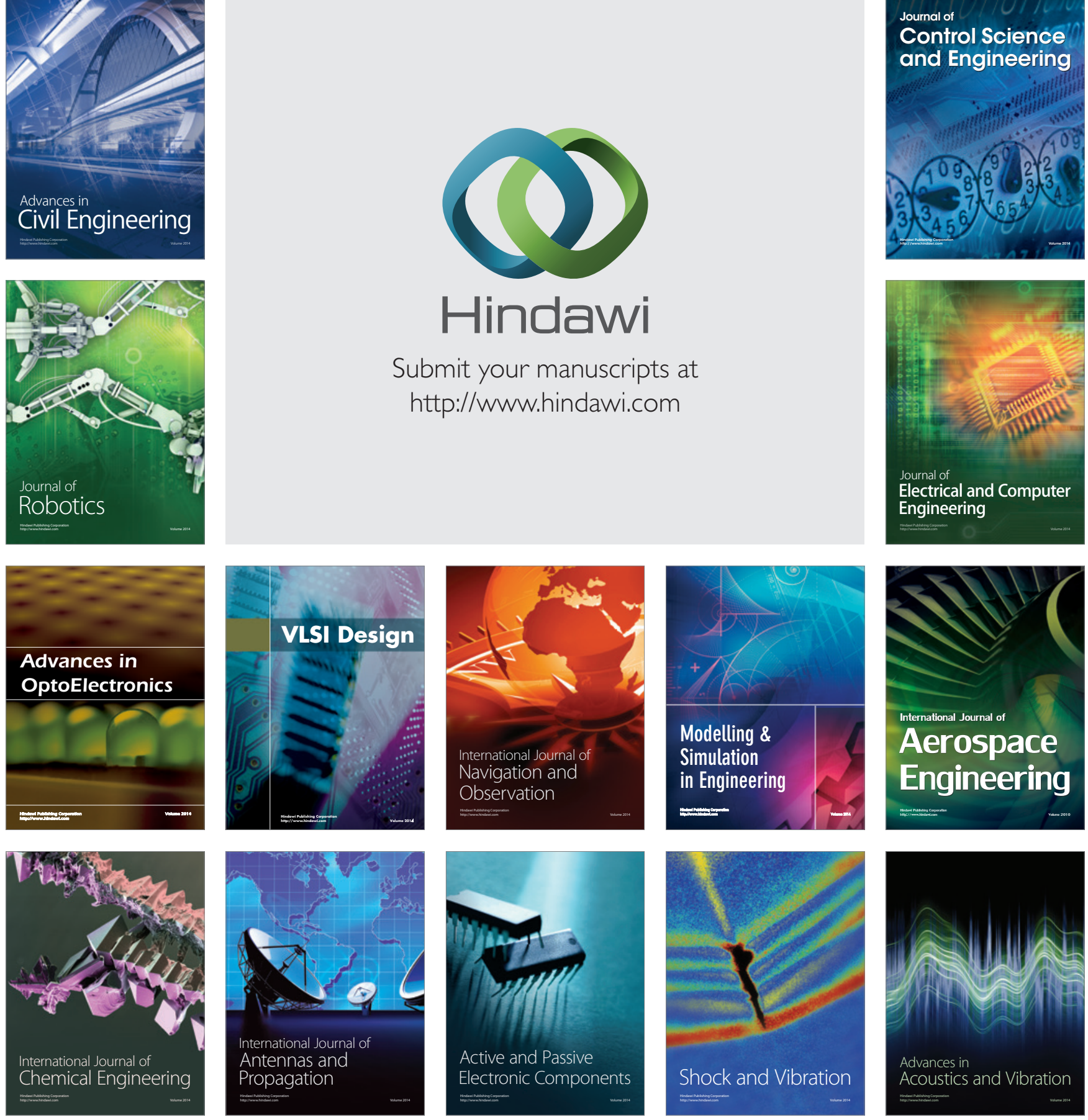